\title{
Growth and Physiological Responses of Four Rose Rootstocks to Drought Stress
}

\author{
Genhua Niu ${ }^{1}$ and Denise S. Rodriguez \\ Department of Horticultural Sciences, Texas AgriLife Research Center at El Paso, Texas A\&M \\ System, 1380 A\&M Circle, El Paso, TX 79927
}

\begin{abstract}
AdDITIONAL INDEX wORDs. gas exchange, Rosa, water relation
Abstract. Drought-tolerant garden roses (Rosa spp.) are needed in arid and semiarid regions where irrigation water is scarce. The vast majority of garden rose cultivars are budded or grafted onto rootstocks and are seldom grown on their own roots. The objective of this study was to compare the growth and physiological responses of four rose rootstocks to drought stress. Rosa $\times$ hybrida 'Dr. Huey', $R$. $\times$ fortuniana, $R$. multiflora, and $R$. odorata grown in $12-\mathrm{L}$ containers were well-irrigated throughout the experiment or were subjected to mild drought stress for five or six cycles, depending on rootstocks, over 10 weeks. Following the mild drought stress cycles, plants that received the mild drought treatment were subjected to a severe dry-down before termination of the experiment. In $R$. $\times$ fortuniana, drought stress did not affect any growth parameter. Compared with the well-irrigated plants, shoot dry weight of 'Dr. Huey', $R$. multiflora, and $R$. odorata were reduced by $22 \%, 33 \%$, and $38 \%$, respectively, by the drought treatment. The final leaf area of $R$. multiflora and $R$. odorata was reduced by $42 \%$ and $59 \%$, respectively, compared with the control plants. The final leaf area of 'Dr. Huey' was not influenced by the drought treatment. Root to shoot ratio in 'Dr. Huey' was unaffected, while that of $R$. multiflora and $R$. odorata increased as a result of the drought treatment. As substrate moisture content decreased, leaf relative water content (RWC) of all rootstocks decreased linearly, with differences in decreasing slope or intercept of the linear regression lines among rootstocks. Predawn leaf water potential during the dry-down began to decrease rapidly when substrate moisture content decreased to below $20 \%(25 \%$ in $R$. odorata) in 'Dr. Huey', $R$. $\times$ fortuniana, and $R$. multiflora. Leaf net photosynthetic rate $\left(P_{n}\right)$, transpiration rate $(E)$ and stomatal conductance $\left(\mathrm{g}_{\mathrm{s}}\right)$ of all rootstocks decreased rapidly during the dry-down as substrate moisture content decreased from $25 \%$. In 'Dr. Huey' and $R$. $\times$ fortuniana, $P_{n}$, E, and $g_{s}$ were closely correlated with leaf RWC, while $E$ and $g_{s}$ of $R$. odorata were not. Correlations between gas exchange rates $\left(P_{n}, E\right.$, and $\left.g_{s}\right)$ and leaf $R W C$ in $R$. multiflora were weaker than those in 'Dr. Huey' and $R$. $\times$ fortuniana. At low substrate moisture content (below $15 \%), P_{n}, E$, and $g_{s}$ in $R$. odorata were lower than those in other rootstocks. Growth reduction was greatest in $R$. odorata, regardless of the least water deficit of the substrate, followed by $R$. multiflora and 'Dr. Huey'. The results of this study suggest that $R$. $\times$ fortuniana was the most tolerant and $R$. odorata was the least tolerant to drought stress.
\end{abstract}

Rose is one of the most common garden plants in the world. Due to its long history of cultivation and popularity, vast information exists on breeding, disease/pest management, culture and propagation, rootstock selection, and postharvest handling (Robert et al., 2003). However, little is known about plant responses to environmental stresses, such as drought stress, which is becoming an increasing concern in arid and semiarid regions. Therefore, in addition to enhancing flower color, size, and fragrance, improving resistance to environmental stresses will be one of the goals in future breeding and biotech programs (Pemberton, 2003).

Plants have developed various mechanisms to tolerate drought stress such as altered root to shoot ratio, smaller and fewer leaves, and altered stomatal function (Blum, 1996). Photosynthesis is the primary process for plant biomass production and is one of the most sensitive physiological processes to environmental stresses (Hsiao and Acevedo, 1974; Huang, 2004). Consequently, the ability to maintain a reasonable rate of photosynthesis under stress conditions can be a good indicator of a plant's adaptability. Hagidimitriou and Pontikis (2005)

Received for publication 14 Nov. 2008. Accepted for publication 18 Mar. 2009. We gratefully acknowledge the financial support from the Cooperative State Research, Education, and Extension Service, U.S. Department of Agriculture under Agreement No. 2005-34461-15661. We also thank Jackson \& Perkins Wholesale, Inc. for donating the plant materials.

${ }^{1}$ Corresponding author. E-mail: gniu@ag.tamu.edu. found that 'Koroneiki', a more drought-tolerant olive (Olea europea) cultivar, performed better and was able to maintain greater leaf photosynthetic rates under high air vapor pressure deficit compared with the other green olive cultivars in the research. In oleander (Nerium oleander), drought-tolerant clones developed more new shoots and had greater shoot growth during a cyclic drought stress period, while those less tolerant to drought had fewer new shoots and less shoot growth (Niu et al., 2008).

Most garden roses are produced by grafting using the Tbudding technique (Pemberton, 2003). Different rootstocks are recommended in various areas in the world in accordance with climatic and soil conditions. For example, R. multiflora is used in the south-central United States, Canada, and Japan, whereas, 'Dr. Huey' is used in the western United States (Pemberton, 2003). Rosa $\times$ fortuniana is used in areas with year-round temperate climate (Morrell, 1983). In the United States, $R$. $\times$ fortuniana is mainly used in Florida, southeastern, and southwestern regions (Martin, 2008). Rosa odorata is one of the most popular rose rootstocks for greenhouse-cut roses $(R$. $\times$ hybrida), but it is also valued for garden roses (Cabrera, 2002; Singh and Chitkara, 1982, 1987). To our knowledge, the only studies on drought tolerance for garden roses were conducted by Henderson et al. (1991) and Henderson-Cole and Davies (1993), who observed cultivar differences in drought tolerance. For greenhouse cut roses, Chimonidou-Pavlidou (1996, 2004) found that drought stress reduced cut flower yield, flower 
quality, and the growth of flowering shoots. For potted miniature roses $(R$. $\times$ hybrida $)$, drought stress during production lowered the postharvest quality (Williams et al., 1999, 2000). Different mechanisms in miniature rose cultivars in tolerating drought stress such as osmotic adjustment and stomata closure were reported (Riseman et al., 2001).

The performance of a grafted rose plant under drought stress depends on the drought tolerance of the scions and the rootstocks and their compatibility (interaction). No research has compared the drought tolerance of various rose rootstocks. Therefore, selection for drought tolerance in roses may begin with drought-tolerant rose rootstocks. In grapevines (Vitis vinifera), drought-tolerant rootstocks were used to improve the performance of the grafted plants under drought conditions (Iacono and Peterlunger, 2000). In citrus (Citrus spp.), it is well known that the inherent differences among rootstocks influence growth, yield, and fruit quality, making the selection of a rootstock an important consideration for a citrus orchard (Castle et al., 1993). Leaf gas exchange of grapevine is affected by rootstock, although this effect is scion-specific (Iacono et al., 1998). Niu and Rodriguez (2008) characterized the growth and ion uptake responses of four rose rootstocks, 'Dr. Huey' $R . \times$ fortuniana, $R$. multiflora, and $R$. odorata, to various salinity levels dominated by chloride or sulfate. However, their response to drought stress remains unknown. Therefore, the objective of this study was to compare the growth, water relations, and gas exchange rates of the same four rose rootstocks in response to drought stress.

\section{Materials and Methods}

Plant materials and cultural Conditions. Rooted cuttings of rose rootstocks, $R$. ×hybrida 'Dr. Huey', $R$. $\times$ fortuniana, $R$. multiflora, and $R$. odorata, were received on 10 Oct. 2006 from a commercial grower (Jackson and Perkins, Medford, OR) and were transplanted to 2.6-L containers. For the substrate, a 1:1 (by vol) mix of Sunshine Mix No. 4 (SunGro Horticulture, Bellevue, WA) and composted mulch (Western Organics, Tempe, AZ) was used and amended with $5 \mathrm{~kg} \cdot \mathrm{m}^{-3}$ powdered dolomite limestone (Carl Pool Earth-Safe Organics, Gladewater, TX) and $1 \mathrm{~kg} \cdot \mathrm{m}^{-3}$ Micromax (Scotts, Marysville, $\mathrm{OH})$. Plants were transplanted again on 28 Feb. 2007 to 12.0-L containers with the same substrate. Plants were grown in a greenhouse and were pruned to uniform heights $(10-12 \mathrm{~cm})$ every 4 to 5 weeks. Greenhouse temperature was controlled by a pad-and-fan cooling system during the summer and by a natural gas heating system during the winter. A shadecloth with $25 \%$ light exclusion was used to cover the greenhouse roof from April to October. Until the initiation of the drought treatments, all plants were well irrigated with a nutrient solution containing $0.5 \mathrm{~g} \cdot \mathrm{L}^{-1}$ of $20 \mathrm{~N}-8.6 \mathrm{P}-16.7 \mathrm{~K}$ (Peters 20-20-20, Scotts). The average air temperature in the greenhouse ranged from 18 to $35{ }^{\circ} \mathrm{C}$ during the experiment (23 Mar.-20 June 2007). The average relative humidity was $37 \% \pm 4 \%$ (mean \pm $\mathrm{SD})$ during the day and $48 \% \pm 7 \%$ at night. The daily light integral $(P A R)$ was $18 \pm 4 \mathrm{~mol} \cdot \mathrm{m}^{-2} \cdot \mathrm{d}^{-1}$. The maximum $P P F$ during the experiment ranged from 650 to $980 \mu \mathrm{mol} \cdot \mathrm{m}^{-2} \cdot \mathrm{s}^{-1}$. The temperature was measured by copper-constantan thermocouples and PPF was measured by a quantum sensor (model QSO-SUN; Apogee Instruments, Logan, UT) every $10 \mathrm{~s}$ and the hourly averages were recorded by a datalogger (21X; Campbell Scientific, Logan, UT).
Mild drought TREATMent (CYCliC DROUght STRESS). Uniform plants of each rootstock were selected and divided into two groups: drought and control. Each treatment had 16 plants for each rootstock. All plants were pruned to uniform heights $(10-12 \mathrm{~cm})$ for all rootstocks on 22 Mar. 2007. Mild drought treatment was initiated on 23 Mar. and ended on 29 May (the last irrigation date). A microspray emitter irrigation system (Roberts Irrigation Products, San Marcos, CA) was used for all plants with two emitters per container. Mild drought stress was imposed by withholding irrigation until a predetermined container weight was reached, which was adjusted for plant weight as plants grew. The target weight was determined to allow incipient wilting to occur at the beginning of the experiment. An irrigation schedule was then determined according to the weights of four indicator containers for each rootstock in the drought treatment. The same nutrient solution aforementioned was applied to all plants at each irrigation event. 'Dr. Huey', R. ×fortuniana, and $R$. multiflora were irrigated seven times (six cycles of mild drought stress), while $R$. odorata was irrigated six times during the 10 -week mild drought treatment period because $R$. odorata was smaller. The control plants were well irrigated throughout the experiment, from weekly at the beginning of a growing cycle to twice per week, according to plant size and weather conditions.

SeVere-drought TReatment (DRY-DOWN). Following the mild drought stress, irrigation was withheld from the plants in the drought treatment beginning on 30 May (68 d after the initiation of mild drought stress) and ended when severe drought stress was reached. The severe drought stress was determined according to pot weight (reflecting substrate volumetric moisture content) and visual stress sign (severe shoot tip wilting). The termination date was 8 June for 'Dr. Huey', $R$. fortuniana, and $R$. multiflora, and 13 June for $R$. odorata. The reason for ending drought stress on 13 June for $R$. odorata was because the plants were smaller after the mild drought stress; therefore, the rate of water loss was slower compared with the other rootstocks and visual stress occurred later. Also, there were several days with much lower temperatures and irradiance after 9 June, which further decreased the water loss of $R$. odorata. Following the severe dry-down, plants were wellirrigated for recovery for 1 week before being harvested for final growth analysis. During the severe dry-down, predawn leaf water potential, leaf gas exchange, container weight (for later calculation of substrate moisture contents and daily evapotranspiration rate), and leaf relative water content (RWC) were measured every other day or daily. Details for these measurements are described below.

Substrate moisture CONTENT. The volumetric substrate moisture content was estimated as the following: [fresh weight of substrate (grams) - dry weight of substrate (grams)]/volume of substrate $($ milliliters $) \times 100 \%$. Fresh weight of substrate $=$ total container weight - shoot and root fresh weight - empty container weight. Dry weight of the substrate was determined by being oven-dried at $80{ }^{\circ} \mathrm{C}$ for 2 weeks. To obtain the substrate matric potential, watermark soil moisture sensors (Irrometer, Riverside, CA) were buried (sensor length: $6 \mathrm{~cm}$ ) $2 \mathrm{~cm}$ below the substrate surface in four containers per rootstock in the drought treatment. The matric potentials were read using a handheld meter at 1030 HR daily. For control, a total of six sensors was used to indicate the matric potential range, which was between 0 (saturated) and about $-15 \mathrm{kPa}$. 
Leaf water potential. Predawn leaf water potentials during the dry-down were determined about every other day on young, fully expanded leaves (leaflets) by using the leaf-cutter psychrometer (J.R.D. Merrill Specialty Equipment, Logan, UT) on three plants with three subsamples (on the same plant). After sampling, the psychrometer sensors were placed in a $25{ }^{\circ} \mathrm{C}$ water bath for $3 \mathrm{~h}$ before the voltage output of the sensors were read by a datalogger (CR7; Campbell Scientific).

RWC. Leaf RWC was determined in midmorning on the same days that leaf water potential and gas exchange rates were measured. Several leaflets (two to five, depending on size) were detached from the plants and were immediately placed in plastic bags and carried to the laboratory where fresh weights (FW) were recorded. Samples were floated in deionized water in a covered petri dish. After $24 \mathrm{~h}$, leaves were dried with tissue paper and the turgid weight (TW) was recorded. Dry weight (DW) was subsequently determined after being ovendried at $70{ }^{\circ} \mathrm{C}$ for $48 \mathrm{~h}$. RWC was calculated as (FW - DW)/ (TW - DW) $\times 100 \%$.

Leaf GaS EXChange. To examine the changes of gas exchange rates in response to substrate drying, leaf net photosynthetic rate, transpiration rate, and stomatal conductance were measured during the dry-down every other day at the beginning of the dry-down and daily at the end. The same plants used for other measurements for each rootstock were selected for $\mathrm{P}_{\mathrm{n}}, \mathrm{E}$, and $\mathrm{g}_{\mathrm{s}}$ measurement by clipping a young, fully expanded leaflet into the leaf chamber (cuvette) of a portable gas exchange system (CIRAS-2; PP Systems, Amesbury, MA). The environmental conditions in the cuvette were controlled at $25^{\circ} \mathrm{C}, 1000 \mu \mathrm{mol} \cdot \mathrm{m}^{-2} \cdot \mathrm{s}^{-1} \mathrm{PPF}$, and $385 \mu \mathrm{mol} \cdot \mathrm{mol}^{-1} \mathrm{CO}_{2}$. Data were recorded when the environmental conditions and gas exchange parameters in the cuvette became stable. These measurements were taken between 1000 and 1200 HR.

Daily water Loss. During the mild cyclic drought stress cycles, daily water loss was calculated as the difference in container weights within a $24-\mathrm{h}$ period. The indicator containers in drought and control treatments were weighed daily at the same time. However, the available data of daily water loss for the control were fewer than the drought due to more frequent irrigations (therefore, data were not shown in Fig. 2).

Growth DETERMination. All plants in both treatments were pruned to a uniform $(10-12 \mathrm{~cm})$ height $39 \mathrm{~d}$ after the initiation of treatment and the pruned fresh weights were recorded immediately and the DW of pruned shoots were determined by being oven-dried at $70{ }^{\circ} \mathrm{C}$ to a constant weight. Upon termination of the experiment, four indicator plants plus another four randomly selected plants for each rootstock were destructively harvested to determine the DW of stems, leaves, and roots. Leaf area was measured using a leaf area meter (LI-3100; LI-COR, Lincoln, NE).

Data Analysis and statistics. The experiment was a splitplot design with drought treatment as the main plot and four rootstocks as the subplot with 16 plants per treatment for each rootstock. A two-way analysis of variance procedure was used to test the effects of drought stress and rootstock on plant growth. When there was an interaction between treatment and rootstock, means were separated from the eight groups by Student-Newman-Keuls (SNK) multiple comparisons. Leaf RWC and gas exchange rates $\left(P_{n}, E\right.$, and $\left.g_{s}\right)$ during the drydown were analyzed by plotting against substrate volumetric moisture content. Linear or quadratic regression analyses were performed to determine the nature and significance of associ- ations between RWC, $\mathrm{P}_{\mathrm{n}}$, E, and $\mathrm{g}_{\mathrm{s}}$ during the dry-down and the substrate moisture content. Linear or quadratic regression was selected based on the significance of quadratic correlation. When the quadratic correction was not significant, a linear regression was chosen. Differences of two lines were analyzed using the GLM procedure by comparing the slopes and intercepts. All statistical analyses were performed using SAS (version 9.1.3; SAS Institute, Cary, NC).

\section{Results}

SubStRate Matric potential. The mean substrate matric potentials $\left(\psi_{\mathrm{m}}\right)$ of the four indicator containers per rootstock throughout the mild cyclic drought stress period and the $\psi_{\mathrm{m}}$ of the control plants averaged across the four rootstocks are shown in Fig. 1. The total number of irrigation events for this cyclic dry-down period was seven (six drought stress cycles) for 'Dr. Huey', R. ×fortuniana, and R. multiflora, and six for R. odorata. A few days before the end of each drought cycle, $R$. odorata generally had less negative substrate $\psi_{\mathrm{m}}$, followed by $R$. $\times$ fortuniana, while 'Dr. Huey' and R. multiflora had more negative substrate $\psi_{\mathrm{m}}$. In a typical cycle, substrate $\psi_{\mathrm{m}}$ for all rootstocks was zero right after irrigation, and the differences in substrate $\psi_{\mathrm{m}}$ among the rootstocks became larger toward the end of the drought cycle. At the end of the second cycle, $R$. multiflora had the most negative $\psi_{\mathrm{m}}$ and 'Dr. Huey' had the second most negative $\psi_{\mathrm{m}}$. In all other drought cycles, $\psi_{\mathrm{m}}$ were generally less negative compared with the second cycle. The trends of the substrate $\psi_{\mathrm{m}}$ values for all rootstocks were consistent with those of container weights (data not shown), which reflected the substrate volumetric moisture contents. Substrate $\psi_{\mathrm{m}}$ in the control ranged from 0 to $-15 \mathrm{kPa}$.

Daily water Loss. During the mild cyclic drought stressed period, daily water loss per pot changed dynamically (Fig. 2). When substrate $\psi_{\mathrm{m}}$ was low at the end of each mild drought stress cycle, daily water loss was also low. Typically, daily water loss was lower immediately after reirrigation and then increased when plants were recovered from the previous stress cycle, and daily water loss decreased again as substrate $\psi_{\mathrm{m}}$

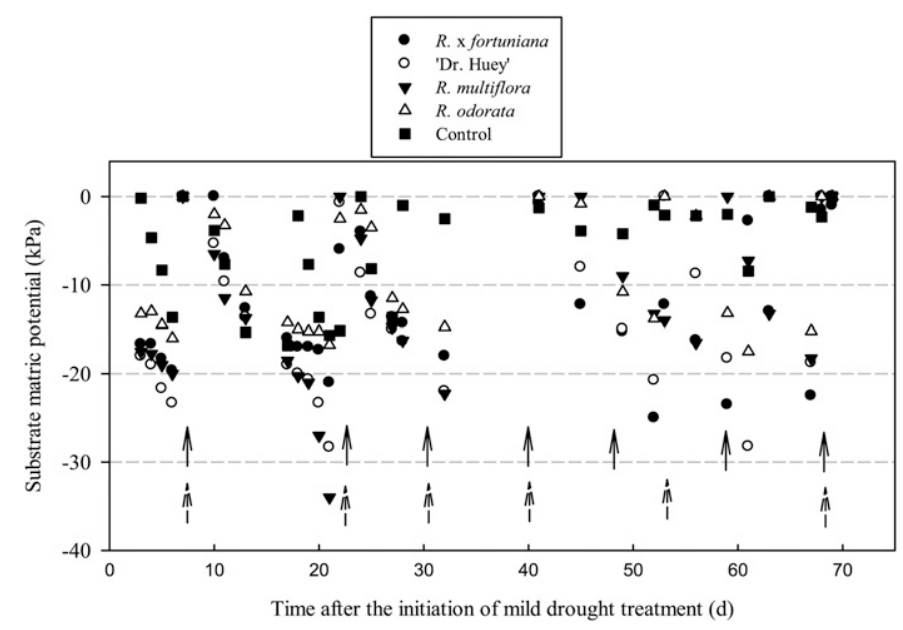

Fig. 1. Substrate matric potential $\left(\psi_{\mathrm{m}}\right)$ during the mild cyclic drought-stressed period for four rose rootstocks: Rosa $\times$ hybrida 'Dr. Huey', $R$. $\times$ fortuniana, $R$. multiflora, and $R$. odorata. Each data point represents mean of four containers of each rootstock. The control represents the mean of six containers averaged across the four rootstocks. The solid arrows indicate irrigation for 'Dr. Huey', $R$. $\times$ fortuniana, and R. multiflora and dashed arrows for $R$. odorata. 


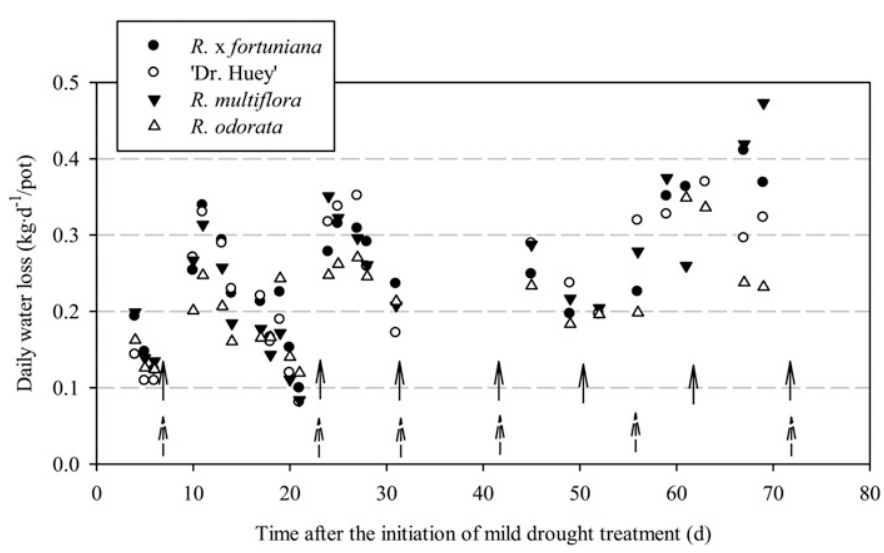

Fig. 2. Daily water loss of the four rose rootstocks (Rosa $\times$ hybrida 'Dr. Huey', $R$. $\times$ fortuniana, $R$. multiflora, and $R$. odorata) subjected to the mild cyclic drought stress. Each data point represents mean of four plants of each rootstock. The solid arrows indicate irrigation for 'Dr. Huey', $R$. $\times$ fortuniana, and $R$. multiflora, and dashed arrows for $R$. odorata.

continued to decrease until the next irrigation event. At the end of the second cycle, daily water loss for 'Dr. Huey' and $R$. multiflora was less than $0.1 \mathrm{~kg} \cdot \mathrm{d}^{-1}$ and that of $R$. $\times$ fortuniana was $0.1 \mathrm{~kg} \cdot \mathrm{d}^{-1}$.

GrowTH. There were interactions between drought treatment and rootstock on all growth parameters, indicating different growth responses to drought stress among rootstocks (Fig. 3). Drought stress did not affect any growth parameter of $R$. $\times$ fortuniana. Compared with the well-irrigated plants, shoot DW of 'Dr. Huey', R. multiflora, and $R$. odorata was reduced by $22 \%, 33 \%$, and $38 \%$, respectively. Drought stress did not affect the root DW of 'Dr. Huey' and $R$. odorata, whereas dry weight of $R$. multiflora was reduced by $15 \%$. Drought stress reduced the total DW by $21 \%$ in 'Dr. Huey' and $29 \%$ in R. multiflora and $R$. odorata. No differences were found in root to shoot ratio between the drought and the control in 'Dr. Huey', while root to shoot ratio of $R$. multiflora and $R$. odorata were increased due to the drought stress. Drought stress did not affect the final leaf area of 'Dr. Huey'. However, leaf area of $R$. multiflora and $R$. odorata were reduced by $42 \%$ and $59 \%$, respectively, compared with the control, due to the drought stress.

RWC. During the severe dry-down at the end of the experiment, as substrate moisture content decreased, RWC of 'Dr. Huey' decreased more rapidly (steepest slope of the regression line) compared with the other rootstocks (Fig. 4). No differences were found when comparing the regression lines between $R$. xfortuniana and $R$. multiflora and between $R$. multiflora and $R$. odorata. However, there was a difference in the two regression lines between $R$. $\times$ fortuniana and $R$. odorata.

Gas eXChange. During the severe dry-down, as substrate moisture content decreased, $\mathrm{P}_{\mathrm{n}}$ for 'Dr. Huey' and $\mathrm{P}_{\mathrm{n}}$ and $\mathrm{E}$ for $R$. $\times$ fortuniana decreased in a quadratic fashion, while those of $R$. multiflora and $R$. odorata decreased linearly (Fig. 5). In the range of substrate moisture content between $10 \%$ to $20 \%$, 'Dr. Huey' and $R$. xfortuniana generally had greater $\mathrm{P}_{\mathrm{n}}, \mathrm{E}$, and $\mathrm{g}_{\mathrm{s}}$ compared with those of $R$. multiflora and $R$. odorata. Also, in this range $(10 \%-20 \%), \mathrm{P}_{\mathrm{n}}, \mathrm{E}$, and $\mathrm{g}_{\mathrm{s}}$ in $R$. Xfortuniana and 'Dr. Huey' were linearly correlated with substrate moisture content $(P<0.0001)$ and the slope of the linear line was steeper in $R$. $\times$ fortuniana than in 'Dr. Huey' $(P<0.05)$. On day $2, R$. odorata had the lowest $P_{n}, E$, and $g_{s}$ compared with those of other

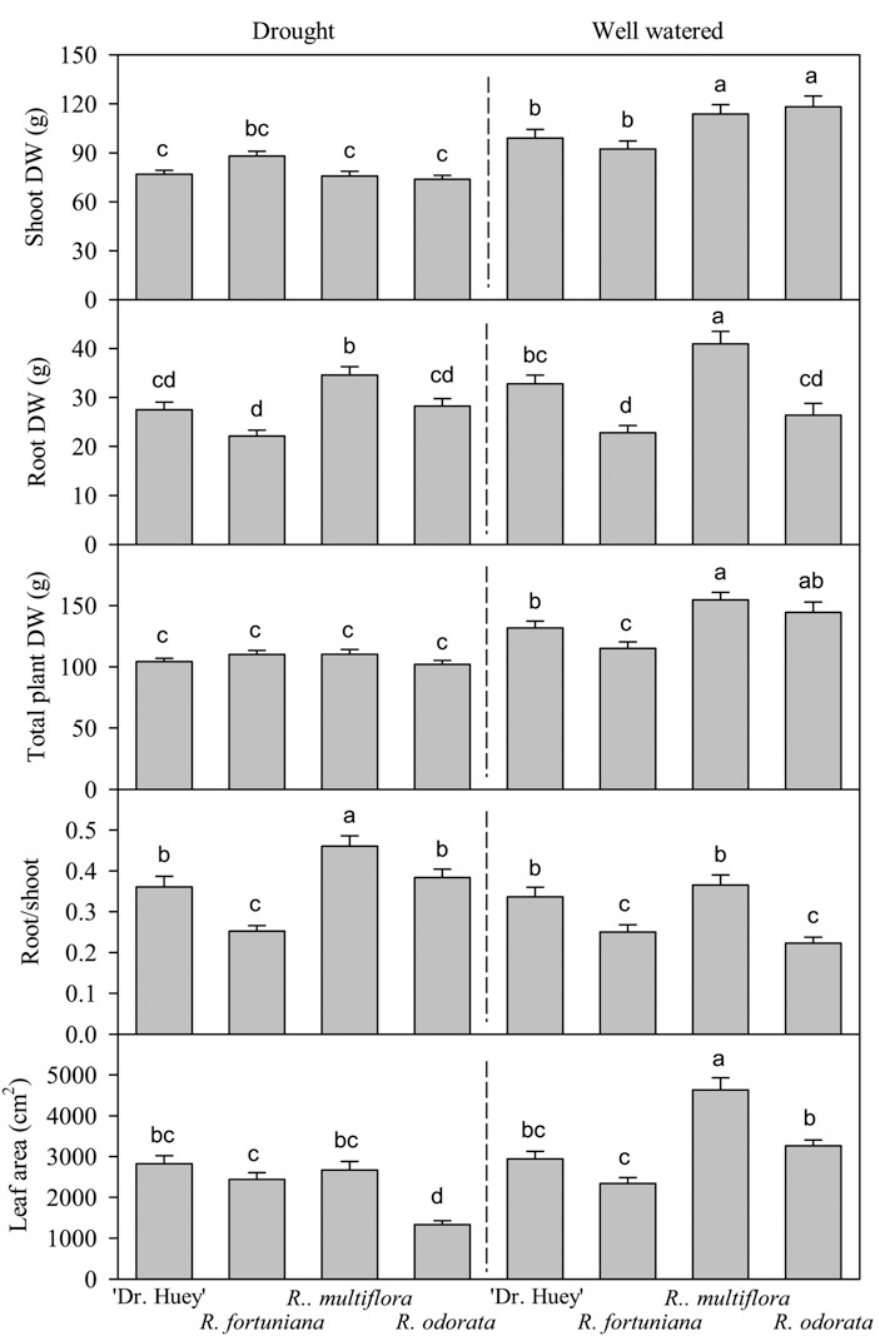

Fig. 3. Shoot dry weight (DW), root DW, total plant DW, root to shoot ratio, and leaf area of four rose rootstocks (Rosa $\times$ hybrida 'Dr. Huey', $R$. $\times$ fortuniana, $R$. multiflora, and $R$. odorata) under well-irrigated cycles or subjected to multiple mild drought stress cycles. Means with same letters are not significantly different according to Student-Newman-Keuls (SNK) at $P<0.05$. Vertical bars represent SE $(\mathrm{n}=8)$.

rootstocks (SNK multiple comparisons at $P=0.05$ ). For ' $\mathrm{Dr}$. Huey' and $R$. $\times$ fortuniana, there were strong correlations $(P<$ $\left.0.0001, \mathrm{r}^{2}=0.80-0.97\right)$ between $\mathrm{P}_{\mathrm{n}}, \mathrm{E}, \mathrm{g}_{\mathrm{s}}$, and RWC, while $\mathrm{E}$ and $\mathrm{g}_{\mathrm{s}}$ of $R$. odorata did not correlate with RWC (Table 1). The correlations between $\mathrm{P}_{\mathrm{n}}, \mathrm{E}, \mathrm{g}_{\mathrm{s}}$, and RWC for R. multiflora were weaker compared with those for 'Dr. Huey' and $R$. $\times$ fortuniana.

Predawn leaf water potential. During the severe drydown, predawn leaf water potential at substrate moisture content above $25 \%$ was similar among all rootstocks (Fig. 6). At substrate moisture contents of $25 \%$ to $15 \%$, leaf water potential was more negative in $R$. odorata when compared with those of the other three rootstocks. There were no differences in the relationships between leaf water potential and substrate moisture content among 'Dr. Huey', $R$. ×fortuniana, and $R$. multiflora.

\section{Discussion}

Drought stress often reduces plant growth and the magnitude of reduction depends on the degree of drought stress and the tolerance of the plant (Hsiao and Acevedo, 1974). 

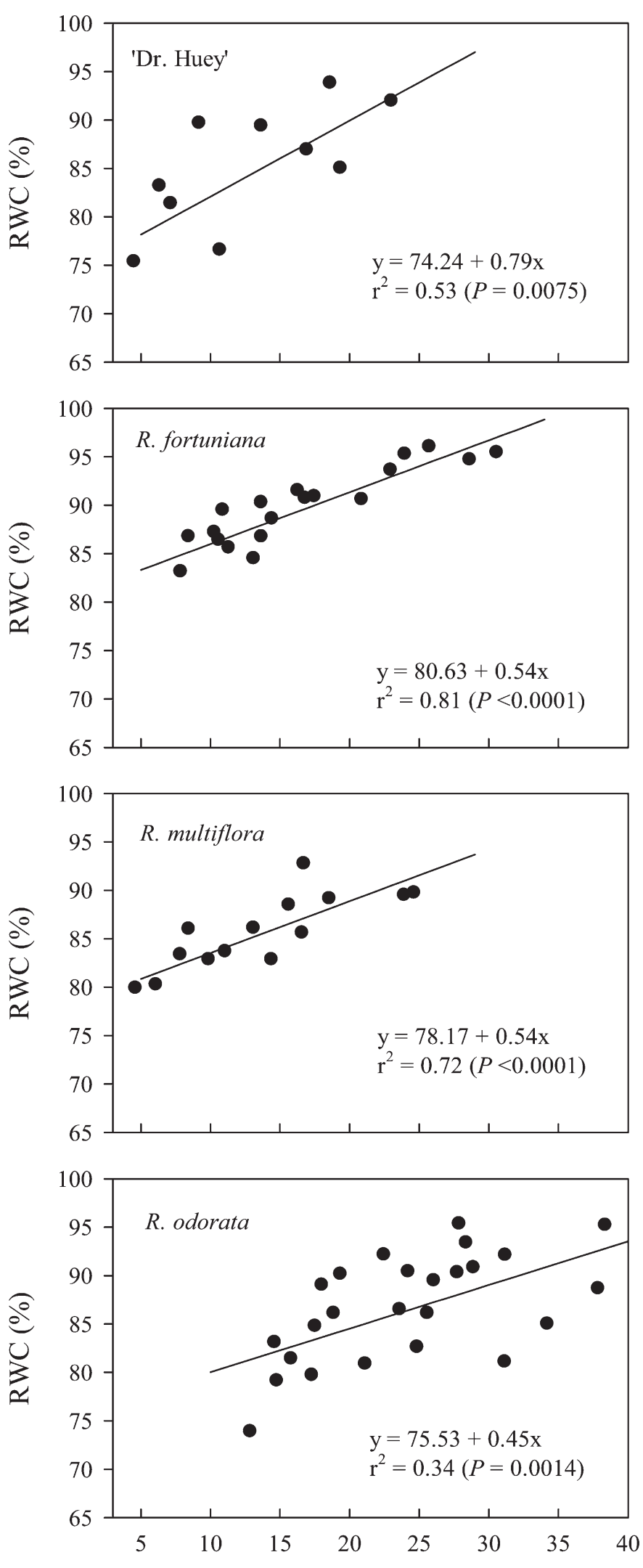

Substrate volumetric moisture content (\%)

Fig. 4. Relationship between leaf relative water content (RWC) and substrate moisture content during the severe dry-down for four rose rootstocks: Rosa $\times$ hybrida 'Dr. Huey', R. ×fortuniana, R. multiflora, and R. odorata.
Drought-tolerant plants should maintain relatively great growth and developmental rates during drought stress (Blum, 1996; Ngugi et al., 2004). In oleander, drought stress inhibited shoot development and growth in less tolerant clones (Niu et al., 2008). The rate of new branching of grapevine was inhibited and the rate of leaf appearance was reduced by drought stress (Lebon et al., 2006). In the present study, drought stress had little effect on the growth of $R$. ×fortuniana, but reduced shoot growth in R. odorata, $R$. multiflora, and 'Dr. Huey'. Regardless of the least drought stress indicated by least negative substrate matric potential, $R$. odorata had the greatest growth reduction and was the most sensitive to drought stress, followed by $R$. multiflora and 'Dr. Huey'.

An increase in root to shoot ratio is a common observation under drought stress, which resulted from a relatively larger decrease in shoot growth than in root growth (Blum, 1996). In this study, the root to shoot ratio in $R$. odorata increased by the drought stress resulted from reduced shoot growth. Root to shoot ratios increased by exposing plants to drought stress in freeman maples (Acer $\times$ freemanii) (Zwack and Graves, 1998), douglas fir (Pseudotsuga menziesii) (Joly et al., 1989), grapevines (Iacono and Peterlunger, 2000), and oleander (Niu et al., 2008) in container-grown plants. Under well-irrigated conditions, 'Dr. Huey' and $R$. multiflora plants had similar and greater root to shoot ratios compared with those of the other two rootstocks. This may indicate superior tolerance capacities of 'Dr. Huey' and R. multiflora during drought stress compared with the other rootstocks under field conditions where root restriction is not significant.

The instantaneous leaf gas exchange rates $\left(\mathrm{P}_{\mathrm{n}}, \mathrm{g}_{\mathrm{s}}\right.$, and $\left.\mathrm{E}\right)$ of all rootstocks were very responsive to decreasing substrate moisture content. However, there were gas exchange differences among rootstocks in response to the decrease of substrate moisture content. For example, lower $\mathrm{P}_{\mathrm{n}}, \mathrm{E}$, and $\mathrm{g}_{\mathrm{s}}$ of $R$. odorata were observed compared with those of other rootstocks at substrate moisture contents between $10 \%$ and $20 \%$. The fact that $\mathrm{E}$ and $\mathrm{g}_{\mathrm{s}}$ of $R$. odorata did not correlate with its RWC (Table 1) may indicate that the regulation of stomata in $R$. odorata at low substrate moisture contents was different compared with other rootstocks. In other words, regardless of RWC or internal leaf water status, stomata in $R$. odorata started to close at higher substrate moisture levels to reduce water loss, which led to reduction in $\mathrm{P}_{\mathrm{n}}, \mathrm{g}_{\mathrm{s}}$ and $\mathrm{E}$. The correlations between gas exchange rates and RWC (Table 1) and those between gas exchange rates and substrate moisture content (Fig. 5) in R. multiflora were weaker compared with those in $R$. ×fortuniana and 'Dr. Huey'. Between $R$. xfortuniana and 'Dr. Huey', $R$. $\times$ fortuniana had greater $\mathrm{P}_{\mathrm{n}}, \mathrm{E}$, and $\mathrm{g}_{\mathrm{s}}$ in the substrate moisture content range of $20 \%$ to $30 \%$, which might indicate that $R$. ×fortuniana had greater potential rates of gas exchange. Drought-tolerant species of Eucalyptus and Nothofagus maintained greater $\mathrm{P}_{\mathrm{n}}$ and $\mathrm{g}_{\mathrm{s}}$ under drought conditions compared with less tolerant species (Ngugi et al., 2004; Sun et al., 1995). Similarly, drought-tolerant cultivars of olive trees maintained greater $\mathrm{P}_{\mathrm{n}}$ under drought stress compared with less tolerant cultivars (Hagidimitriou and Pontikis, 2005).

We observed that gas exchange rates of these rootstocks took days to recover from drought stress, which is evidenced by the lower $P_{n}, E$, and $g_{s}$ on the second day of the dry-down (Fig. 5). Similar results of slow recovery of gas exchange rates were reported in freeman maples (Zwack and Graves, 1998), potted miniature rose (Williams et al., 1999), and Salvia splendens 

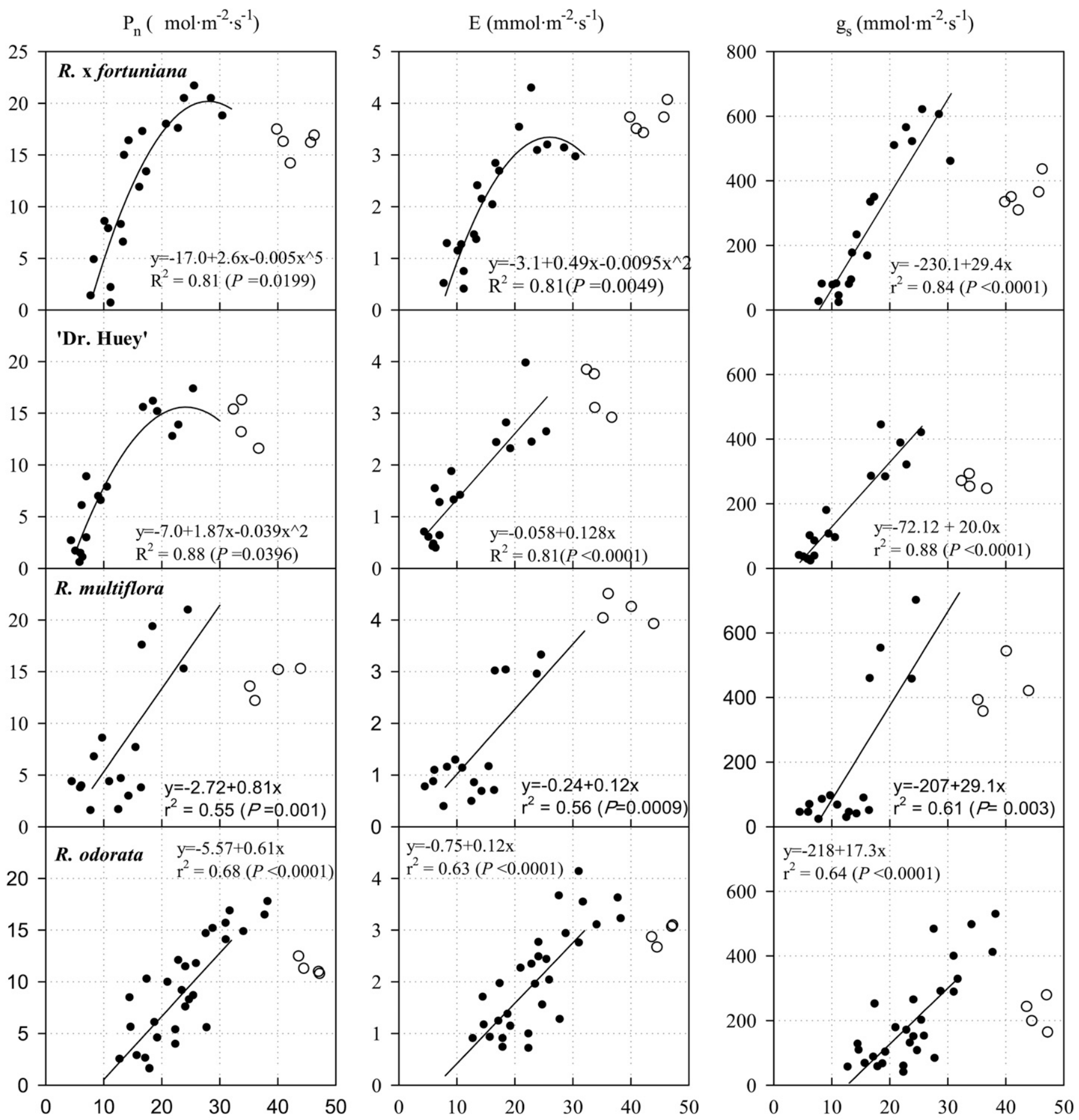

Substrate volumetric moisture content (\%)

Fig. 5. Relationship between leaf net photosynthetic rate $\left(\mathrm{P}_{\mathrm{n}}\right)$, transpiration rate $(\mathrm{E})$, and stomatal conductance $\left(\mathrm{g}_{\mathrm{s}}\right)$ and the substrate moisture content for four rose rootstocks (Rosa $\times$ hybrida 'Dr. Huey', $R$. xfortuniana, $R$. multiflora, and $R$. odorata) measured during the severe dry-down. The open symbols represent data measured on the second day of the severe dry-down when plants were not fully recovered from the previous drought stress. The regression analysis excluded the data on the second day.

'Bonfire' (Eakes et al., 1991). Further research is needed for these rose rootstocks to investigate the differences in recovery ability of gas exchange rates from drought stress.

Leaf water potential is widely used as a parameter to indicate the level of plant water stress. More negative predawn leaf water potentials reflect limited water availability to roots or an ineffective water conducting system (Zwack and Graves, 1998). We noticed that predawn water potential decreased rapidly after substrate moisture content decreased to a critical value (Fig. 6). This critical value is $\approx 20 \%$ for 'Dr. Huey', 
Table 1. Correlation between leaf relative water content (RWC) and net photosynthetic rate $\left(\mathrm{P}_{\mathrm{n}}\right)$, leaf transpiration rate $(\mathrm{E})$, and stomatal conductance $\left(\mathrm{g}_{\mathrm{s}}\right)$ of four rose rootstocks (Rosa $\times$ hybrida 'Dr. Huey', R. ×fortuniana, R. multiflora, and R. odorata) measured during the severe dry-down.

\begin{tabular}{|c|c|c|c|c|c|c|}
\hline \multirow[b]{2}{*}{ Rootstock } & \multicolumn{2}{|c|}{$\mathrm{P}_{\mathrm{n}}$} & \multicolumn{2}{|l|}{$\mathrm{E}$} & \multicolumn{2}{|l|}{$\mathrm{g}_{\mathrm{s}}$} \\
\hline & $P$ value & $\mathrm{r}^{2}$ & $P$ value & $\mathrm{r}^{2}$ & $P$ value & $\mathrm{r}^{2}$ \\
\hline 'Dr. Huey' & 0.0001 & 0.83 & $<0.0001$ & 0.97 & $<0.0001$ & 0.87 \\
\hline R. $\times$ fortuniana & $<0.0001$ & 0.86 & $<0.0001$ & 0.80 & $<0.0001$ & 0.93 \\
\hline R. multiflora & 0.0032 & 0.69 & 0.0021 & 0.71 & 0.0076 & 0.64 \\
\hline R. odorata & 0.0194 & 0.46 & NS & & NS & \\
\hline
\end{tabular}

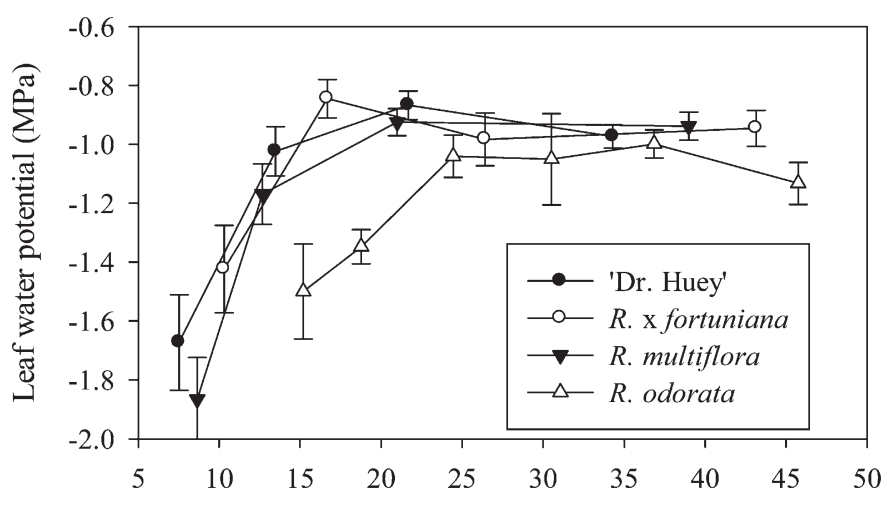

Substrate volumetric moisture content (\%)

Fig. 6. The relationship between the predawn leaf water potentials during the severe dry-down and the substrate moisture content for four rose rootstocks: Rosa $\times$ hybrida 'Dr. Huey', R. ×fortuniana, R. multiflora, and $R$. odorata. Vertical bars represent SE $(n=4)$.

$R$. $\times$ fortuniana, and $R$. multiflora, and higher for $R$. odorata. To examine the subtle changes in leaf water potential as substrate moisture decreases or to examine the differences among genotypes in leaf water potential responses to soil/substrate drying, more frequent measurements are necessary around the critical substrate moisture content. Slowing down the drought stress development may be another option. Similar phenomenon of rapid decrease in leaf water potential around the critical substrate moisture content was observed in oleander (Björkman et al., 1980; Niu et al., 2008). Henderson et al. (1991) reported differences in leaf water potential measured in the afternoon among five cultivars of landscape roses being subjected to drought stress. However, no other parameters indicating the degree of drought stress such as RWC and soil moisture contents are reported. Therefore, it is unknown whether the differences in leaf water potential of these garden roses were caused by different degrees of drought stress.

Leaf water potential, RWC, and instantaneous leaf gas exchange $\left(\mathrm{P}_{\mathrm{n}}, \mathrm{g}_{\mathrm{s}}\right.$, and $\left.\mathrm{E}\right)$ are important parameters that influence water relations in these rose rootstocks. The differences in these physiological responses to substrate drying among the rootstocks led to the differences in their final growth. Apparently, the impact of drought stress was greatest on $R$. odorata, regardless of the least water deficit of the substrate. Among the other three rootstocks, $R$. $\times$ fortuniana may be the most tolerant to drought stress based on lack of growth reduction, although their differences in instantaneous gas exchange may be not straightforward. Relatively small differences in instantaneous $\mathrm{P}_{\mathrm{n}}$ may have a cumulative effect over time, resulting in significant difference in a prolonged period of time. In grapevines, the transfer of drought tolerance of rootstocks was affected by the combination of rootstock and scion due to their interaction (Iacono et al., 1998). Therefore, further research is needed to investigate if the relative drought tolerance of scions grafted or budded onto these rose rootstocks would be consistent with that obtained in this study.

\section{Literature Cited}

Björkman, O., W.J.S. Downton, and H.A. Mooney. 1980. Response and adaptation to water stress in Nerium oleander. Carnegie Institution. Washington Year Book 79:150-157.

Blum, A. 1996. Crop responses to drought and the interpretation of adaptation. Plant Growth Regulat. 20:135-148.

Cabrera, R.I. 2002. Rose yield, dry matter partitioning and nutrient status responses to rootstock selection. Scientia Hort. 95:75-83.

Castle, W.S., D.P.H. Tucker, A.H. Krezdorn, and C.O. Youtsey. 1993. Rootstocks for Florida citrus. 2nd ed. Univ. Florida, Coop. Ext. Serv. Publ. SP 42.

Chimonidou-Pavlidou, D. 1996. Effect of water stress at different stages of rose development. Acta Hort. 424:45-51.

Chimonidou-Pavlidou, D. 2004. Malfunction of roses due to drought stress. Scientia Hort. 99:79-87.

Eakes, D.J., R.D. Wright, and J.R. Seiler. 1991. Moisture stress conditioning effects on Salvia splendens 'Bonrire'. J. Amer. Soc. Hort. Sci. 116:716-719.

Hagidimitriou, M. and C.A. Pontikis. 2005. Seasonal changes in $\mathrm{CO}_{2}$ assimilation in leaves of five major Greek olive cultivars. Scientia Hort. 104:11-24.

Henderson, J.C., F.T. Davies, and H.B. Pemberton. 1991. Landscape rose response to low moisture levels and a hydrophilic gel. Scientia Hort. 46:129-135.

Henderson-Cole, J.C. and F.T. Davies. 1993. Drought response of low and high maintenance landscape roses. J. Environ. Hort. 11:59-63.

Hsiao, T.C. and E. Acevedo. 1974. Plant responses to water deficits, water use efficiency, and drought resistance. Agr. Meteorol. 14:59-84. Huang, B. 2004. Recent advances in drought and heat stress physiology of turfgrass: A review. Acta Hort. 661:185-192.

Iacono, F., A. Buccella, and E. Peterlunger. 1998. Water stress and rootstock influence on leaf gas exchange of grafted and ungrafted grapevines. Scientia Hort. 75:27-39.

Iacono, F. and E. Peterlunger. 2000. Rootstock-scion interaction may affect drought tolerance in Vitis vinifera cultivars: Implications in selection programs. Acta Hort. 528:543-549.

Joly, R.J., W.T. Adams, and S.G. Stafford. 1989. Phenological and morphological responses of mesic and dry site sources of coastal douglas-fir to water deficit. For. Sci. 35:987-1005.

Lebon, E., A. Pellegrino, G. Louarn, and J. Lecoeur. 2006. Branch development controls leaf area dynamics in grapevine (Vitis vinifera) growing in drying soil. Ann. Bot. (Lond.) 98:175-185.

Martin, D. 2008. An overview of Rosa fortuniana rootstock. 31 Jan. 2008. <http://www.pswdistrict.org/text/articles/rosaFortuniana Rootstock.html>.

Morrell, D.L. 1983. The roots of fortuniana ( $R . \times$ fortuniana). Amer. Rose Annu. 1983:55-72.

Ngugi, M.R., D. Doley, and M.A. Hunt. 2004. Physiological responses to water stress in Eucalyptus cloeziana and E. argophloia seedlings. Trees (Berl.) 18:381-389.

Niu, G. and D.S. Rodriguez. 2008. Responses of growth and ion uptake of four rose rootstocks to chloride or sulfate dominated salinity. J. Amer. Soc. Hort. Sci. 133:663-669.

Niu, G., D.S. Rodriguez, and W. Mackay. 2008. Growth and physiological responses to drought stress in four oleander clones. J. Amer. Soc. Hort. Sci. 133:188-196.

Pemberton, H.B. 2003. Overview of roses and culture, p. 570-573. In: A.V. Robert, T. Debener, and S. Gudin (eds.). Encyclopedia of rose science, Vol. 2. Elsevier Academic Press, San Diego. 
Riseman, A., C. Jensen, and M. Williams. 2001. Stomatal conductivity and osmotic adjustment during acclimation to multiple cycles of drought stress in potted miniature rose (Rosa $\times$ hybrida). J. Hort. Sci. Biotechnol. 76:138-144.

Robert A.V., T. Debener and S. Gudin (eds.). 2003. Encyclopedia of rose science. Elsevier Academic Press San Diego.

Singh, B.P. and S.D. Chitkara. 1982. Effect of different salinity and sodicity levels on establishment and bud take performance of various rose rootstocks. Haryana J. Hort. Sci. 11:204207.

Singh, B.P. and S.D. Chitkara. 1987. Effect of different salinity levels on water potential and proline content in leaves of various rose rootstocks. Indian J. Hort. 44:265-267.
Sun, O.J., G.B. Sweet, D. Whitehead, and D. Graeme. 1995. Physiological responses to water stress and waterlogging in Nothofagus species. Tree Physiol. 15:629-638.

Williams, M., E. Rosenqvist, and M. Buchhave. 1999. Response of potted miniature roses (Rosa $\times$ hybrida) to reduced water availability during production. J. Hort. Sci. Biotechnol. 74:301-308.

Williams, M., E. Rosenqvist, and M. Buchhave. 2000. The effect of reducing production water availability on the post-production quality of potted miniature roses (Rosa $\times$ hybrida). Postharvest Biol. Technol. 18:143-150.

Zwack, J.A. and W.R. Graves. 1998. Leaf water relations and plant development of three freeman maple cultivars subjected to drought. J. Amer. Soc. Hort. Sci. 123:371-375. 